\title{
A Preliminary Study on Cost Accounting of Carbon Accounting Based on Environmental Capital Dependence
}

\author{
Jing Ge, Yan Zhang, ShiBao Yang \\ The Engineering \& Technical College of Chengdu University of Technology, Leshan, Sichuan, China
}

Keywords: Environmental capital; Path dependence; Carbon accounting; Cost accounting.

\begin{abstract}
As the third path dependence of modern enterprises' survival and development, environmental capital is an indispensable capital form for the sustainable development of economic society and enterprises. The global climate warming and the frequency of extreme weather have aroused wide public concern and their deep reflection on environmental issues. The investigation of the low carbon economy development level of enterprises must rely on relevant cost accounting of carbon accounting on energy conservation and emission reduction.
\end{abstract}

\section{Introduction}

In recent years, the frequent occurrence of haze in several cities in China has adversely affected the economic and social development of our country, which has aroused wide public concern and profound reflection on environmental issues. All of these environmental problems are directed at the extensive form of economic development which is based on high energy consumption and high emission of waste. The Comprehensive Work Plan for Energy Conservation and Emission Reduction in the 13th Five-year Plan issued by the State Council in January of 2007 required to further implement the general secretary Xi's spirit of the series of speech, to carry out the basic national policy of resource conservation and environmental protection, to set the goal of improving the energy efficiency and ecological environmental quality, to ensure completing the binding target of energy conservation and emission reduction of the 13th five-year plan, so as to promote the economic transformation and upgrading. In order to achieve these goals, it is urgent to change the phenomenon of current severe environmental pollution, reduce the occurrence rate of haze, and seek the economic development model ensuring both economic development and the ecological protection. The low-carbon economy characterized by low consumption and low emission is fit for this demand. In the current context, the promotion of low-carbon economy is a win-win choice for China to deepen industrial reform, seek sustainable development of national economy and realize the harmonious development of social economy and nature.

Accounting is to carry out overall, comprehensive, continuous and systematic accounting and supervision to the economic activities of a certain enterprise or organization by specialized technical methods. It is also an economic management activity that provides accounting information, participates in business management and aims to improve economic efficiency. The low-carbon economy must rely on matching accounting tools and management tools to achieve rapid long-term development. The first is to analyze the relevant accounting and the influence of its disclosure under the low-carbon economic model, and thus restrain the energy conservation and emission reduction behaviors of relevant enterprises in the process of production and operation. However, the traditional accounting based on extensive economic development mode can't take on the accounting and management related to carbon. It is also unable to do scientific evaluation on the low carbon economy development level of the enterprises. Moreover, it is unable to find the enterprises' problems in energy conservation and emission reduction. 
In October 2011, the National Development and Reform Commission (NDRC) approved that seven provinces (Beijing, Tianjin, Shanghai, Chongqing and the other three) could carry out pilot projects on carbon emission trading from 2013 to 2015. In 2017, the NDRC has made clear that there will be a national carbon market and the three industries including electricity, electrolytic aluminum and cement are expected to be among the first batch. The carbon trading market introduces the ecological phenomenon into the accounting treatment of enterprises, so that carbon accounting can be generated and developed. With the academic research on carbon accounting, it has gradually penetrated into other fields of general accounting. Matters like Carbon cost accounting, carbon management accounting, carbon audit, and carbon strategy management accounting have become the expanding new content of carbon accounting.

\section{The Relationship between Environmental Capital Dependence and Cost Accounting of Carbon Accounting}

Environmental capital is an indispensable capital form of sustainable development of economic society and enterprises based on natural resources and ecological environment. Tracing of modern enterprise development history, in the traditional enterprise model of "double path dependence" (the material capital dependence and the human capital dependence), the two rights of enterprises are separated with each other, the enterprises are responsible for the stakeholders. Enterprises put economic interests in the first place, while ignoring environmental protection. According to Pigou's "externality theory", traditional enterprises get higher yield rate than low carbon enterprises. The result is a serious blow to low-carbon enterprises committed to energy conservation and emission reduction and clean energy development, which further aggravates enterprises' reliance on "carbon energy". To solve this kind of awkward situation and realize carbon unlocking fundamentally, we must rely on carbon accounting of the related costs and benefits. With the gradual transformation of the national economic development model to circular economy and low carbon economy, the environment capital has been added into the explanation of enterprises' motivation, and has become the third path dependence, which will gradually evolve into vital strategic capital of the new economic form in the future. With the expansion of the definition of wealth capital and the change in the way of investment, its responsibility is no longer just to share, but to control and restrain. If the enterprises still follow the traditional economic development model which is characterized by high carbon dependence, they are bound to violate national development targets and planning. They also won't conform to the public's value orientation and moral standards, which will weaken its market competition ability. Without the pressure of environmental constraint such as energy conservation and emission reduction, the enterprises will lose the consciousness and the power of technology innovation, system innovation and market innovation. They cannot achieve the strategic shift of high value-added industries. That means the sustainable development cannot be achieved. Thus, enterprises must consciously take the responsibility for the maintenance, promotion and protection of natural ecological environment, and reduce the negative externality of enterprises to the lowest possible level. Therefore, the key subject matter that the carbon accounting research needs to solve is the relation and connotation of environmental capital and carbon accounting theory. The realization of energy conservation and emission reduction required by low carbon economy will cause series of problems about carbon accounting elements, trading rights, carbon performance, information disclosure, and carbon accounting evaluation index system. The thought origin of carbon accounting comes from environmental accounting, which has been developed for more than 30 years and has been further studied in China. Although China has achieved relatively fruitful results in theory and practice, it is still a long way from the requirement of low-carbon economy development.

\section{The Target of Cost Accounting of Carbon Accounting Based on Environmental Capital Dependence}

The highlighted environmental problems and the implementation of low-carbon economy have made people like enterprises' owners, governments, business partners, customers become the 
followers of the information about energy conservation and emission reduction of the enterprises. Under the traditional enterprises' "dual path dependence", the calculation of product cost only includes the material cost and manpower cost of the products, the environmental cost is not included in the list. Such a cost accounting system and the resulting pricing mechanism will inevitably lead to distortion of product costs, which will not be able to exert cost restraint and control in enterprises with high carbon consumption. After the environmental capital becomes the third path dependence, the cost accounting of the enterprises should also be adjusted accordingly. According to the principle of cost burden, the expenses of energy conservation and emission reduction occurred in enterprise economic activities should be borne by the products produced by enterprises. Adding environmental cost including the cost of energy conservation and emission reduction into the cost of products, and accounting on the various cost in the process of energy conservation and emissions reduction (including cost internalization caused by environmental capital, the transformation of derivative and virtual cost to production cost caused by the low carbon standard, the long-term cost caused by low carbon technology investment, the cost change caused by the clean production, etc.). Only in this way can we provide more accurate cost information for the pricing of the product, so that the cost of natural resources can be compensated from the price of the product. Therefore, the goal of carbon cost accounting is to reflect the consumption of carbon resources in the production and operation activities of enterprises, and report the price paid by enterprises to meet the obligations of energy conservation and emission reduction.

\section{The Definition and Accounting of Carbon Accounting Cost}

The Definition of Carbon Accounting Cost. Carbon accounting cost refers to the total outflow of economic benefits produced in the development of low-carbon economy, and in the process of seeking energy conservation and emission reduction, and carbon unlocking, or generated in the carbon emission, which can reduce the owner's equity, and have nothing to do with possessors' allocation. According to the range of cost, it can be divided into internal and external cost. Internal cost refers to the cost undertake by enterprises in order to achieve low carbon targets. Such as the research and development cost of the technical innovation and the transformation in the process of carbon unlocking, the cost happened when enterprises use new energy instead of the original carbon energy, the cost of carbon emission trading, etc. External cost refers to the cost paid by external subjects instead of enterprises themselves for the negative impact on the natural environment due to the weak measures of energy conservation and emission reduction. For example, the excessive carbon pollution discharged by enterprises which did not take responsibility for it.

The Accounting of Carbon Accounting Cost. The Affirmation of Carbon Accounting Cost. The first condition of carbon accounting cost affirmation is whether the matter that causes carbon accounting cost has occurred. The key is to determine whether enterprises' transactions and other matters are related to carbon unlocking and carbon emission. The form is the outflow of assets, the loss of assets and the increase in liabilities.

The Accumulation of Carbon Accounting Cost. The key to the accumulation of carbon accounting cost is the question of capital or cost. In the process of accumulation, the rationalization principle should be followed, that is, if the cost can have a positive effect on the survival of the enterprise and the future benefits, it should be capitalized. For example, in order to meet the goal of energy conservation and emission reduction, the company will pay additional cost when developing new technologies or updating the current equipments. But in the concrete operation, if the cost will not influence the future economic benefits of the enterprises or has no causal relationship with the economic benefits, which means it can't bring the expected economic benefits for the enterprises, then it shouldn't be capitalized aimlessly. It should be reckoned in the current profit and loss as the cost. Such as the purchase of the carbon emission right, the penalty for violation of the emissions, etc. If the cost is not related to energy saving and emission reduction, or can't be affirmed, then it can't be accumulated as carbon accounting cost.

The Measurement of Carbon Accounting Cost. The measurement of carbon accounting should be based on currency metering, supplemented by diversified methods such as physical objects and 
technology. Speaking of measurement attributes, the measurement model should be based on historical cost measurement attribute, supplemented by diversified metering attributes, such as fair value. In the specific operation, since the cost of carbon unlocking is more complex and special than the traditional cost accounting, the enterprises can select the most suitable measurement method based on the actual situation. The main methods available are:

Table 1 The Measurement of Carbon Accounting Cost

\begin{tabular}{|c|c|c|c|}
\hline & Name & Operational approach & Range of application \\
\hline \multirow{2}{*}{ 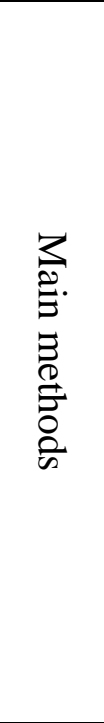 } & $\begin{array}{l}\text { Full amount } \\
\text { method }\end{array}$ & $\begin{array}{l}\text { Measuring according to the } \\
\text { actual total amount in the event } \\
\text { of carbon accounting cost. }\end{array}$ & $\begin{array}{l}\text { Special expenditures for carbon } \\
\text { unlocking and energy conservation } \\
\text { and emission reduction: Carbon } \\
\text { unlocking technology research and } \\
\text { development expenditure, trading } \\
\text { expenses of the carbon emission } \\
\text { right, etc. }\end{array}$ \\
\hline & $\begin{array}{l}\text { Difference } \\
\text { method }\end{array}$ & $\begin{array}{l}\text { If the total cost includes } \\
\text { non-low carbon cost, } \\
\text { measuring according to the } \\
\text { total amount deducting the } \\
\text { same kind of investment } \\
\text { spending without energy } \\
\text { conservation and emission } \\
\text { reduction functions. }\end{array}$ & $\begin{array}{l}\text { Investment in fixed assets with } \\
\text { energy conservation and emission } \\
\text { reduction function: the purchase of } \\
\text { low-carbon machinery with } \\
\text { technological innovation }\end{array}$ \\
\hline \multirow{2}{*}{ 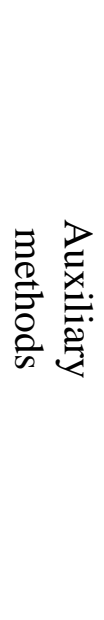 } & $\begin{array}{l}\text { Compensation } \\
\text { method }\end{array}$ & $\begin{array}{l}\text { Measuring by the cost spent in } \\
\text { compensating or } \\
\text { administrating the polluted air. }\end{array}$ & $\begin{array}{l}\text { The expenditures of controlling } \\
\text { the pollution caused by the } \\
\text { enterprises who can't realize the } \\
\text { energy conservation and emission } \\
\text { reduction, or are unable to meet the } \\
\text { emission requirements. }\end{array}$ \\
\hline & $\begin{array}{l}\text { Market } \\
\text { valuation } \\
\text { method }\end{array}$ & $\begin{array}{l}\text { Measuring by the economic } \\
\text { loss of the environment caused } \\
\text { by the enterprises. }\end{array}$ & $\begin{array}{l}\text { The responsibility of the } \\
\text { enterprises for reducing the } \\
\text { economic benefits of other } \\
\text { industries due to the negative impact } \\
\text { of discharging greenhouse gases } \\
\text { which are not up to the standard on } \\
\text { the surrounding environment. }\end{array}$ \\
\hline
\end{tabular}

In practice, the aspect of human development can be taken into consideration according to the specific situation. For example, The air pollution caused by greenhouse gas emission can do great harm to human health, leading to a significant increase in the incidence of a series of respiratory and related diseases. And the increase of the patients will inevitably have adverse effects on social production, resulting in the economic loss. This part of the loss can also be included in the cost measurement.

\section{Summary and Revelation}

Traditional enterprises of double path dependence are more concerned with economic benefits. In the context of today's efforts to develop low-carbon economy, it is the only way for modern enterprises to integrate environmental capital into the optimal resource allocation system. From the angle of environment capital dependence, focusing on the core idea of energy conservation and emission reduction, this paper introduces the environment capital externality into the internal accounting of the enterprises, and puts forward the goal, the definition and the methods of the cost accounting of carbon accounting. However, it is difficult to construct and practice the cost accounting 
of carbon accounting in the current context. The first is the lack of supporting laws and regulations to implement carbon accounting. Current laws and regulations have little to do with greenhouse gas emission. The Accounting Law, Audit Law and other professional regulations also have no explicit provisions on the accounting of corporate carbon information. The second is the lack of clear carbon accounting standards. Although some academic achievements have been formed in the study of carbon accounting in our country, the details are not clear. The core content related to the cost accounting of carbon accounting such as measurement methods and attributes has not been fully determined. The third is the inchoate carbon accounting system. In recent years, Chinese scholars have studied carbon accounting in many ways, but they have not formed an acknowledged and systematic theoretical system. In September 2016, the Ministry of Finance promulgated the Interim Provisions (Exposure Draft) on Accounting Treatment for the Trading Pilots of the Carbon Emission Right. This has a positive and profound significance for the study of carbon accounting, but there is still a long way to go to complete the accounting system. The fourth is the lack of professional technical talents for the development of carbon accounting. The training programs for accounting majors in universities and technical secondary schools rarely involve in the frontier knowledge. It is a dead zone for the study of the emerging disciplines that have not yet formed an exact theoretical system. This has led to the lack of knowledge of carbon accounting for the current accounting practitioners, and the lack of professional and technical talents who are capable of carrying out related business operations. At present, China's carbon trading system is still in its infancy, and the national carbon trading market is about to start. With the thorough development of low carbon economy, the role of energy conservation and emission reduction in enterprises is becoming more and more important. The study of carbon cost accounting must also be deepened. These practical difficulties need to be solved one by one.

\section{Acknowledgements}

Project: The project of the research fund of the Engineering \&Technical College of Chengdu University of Technology in 2016: Research on Theoretical Innovation of Carbon Accounting (Approval Number: C112016011) the stage research achievement.

\section{References}

[1] Jia-Yue Liu, Qiong Zhou, Can-Hui Liu. Study on the Mechanism of Endogenous Low Carbon Capital Growth Based on Environmental Constraints [J], Management World, 2013(10).

[2] Cai-Yun Jing. The Third Path Dependence of Environmental Capital and Modern Enterprises [J], The Collected Papers of the 18th Annual Conference of the Higher Engineering Branch of the Chinese Academy of Accounting(2011), 2011(10).

[3] Yue-Jun Tang, De-Fu Li. Environmental Capital, Negative Externality and Carbon Finance Innovation [J], China Industrial Economics, 2010 (6).

[4] Wang-Feng Zhang. Discussion on Accounting Confirmation and Measurement of the Carbon Emission Right [J], Communication of Finance and Accounting (Integrated Version), 2016 (28).

[5] Ting-Zhang Wang. Thoughts on Accounting of the Carbon Emission Right under Low Carbon Economy [J], Commercial Accounting, 2016 (19). 